\title{
Devolvendo a Dignidade e Autonomia: Cartografia de um Cuidado
}

\author{
Soares, Rosimeire Angela de Queiroz; Machado, Ana Lucia; Bigato, Karen Steagall; Santos, \\ Livia Giubilei; Pigozi, Pamela Lamarca; Cozzani, Rosana Regina; Santos, Sara Giubillei \\ Escola de Enfermagem da USP — enfqueirozrose@yahoo.com.br
}

Introdução: a fibrose cística é uma doença crônica e progressiva de alta prevalência em indivíduos caucasianos, afetando preferencialmente os sistemas digestório e respiratório. Caracteriza-se por infecções pulmonares agudas e crônicas repetidas levando a insuficiência e falência respiratória, dificultando a realização de atividades básicas, evoluindo para alto grau de dependência física e incapacitação. Objetivo: Relatar a experiência de uma enfermeira e doutoranda em ciências da saúde, em um hospital escola, no cuidado prolongado a um paciente com fibrose cística. Método: o método escolhido é o da cartografia, a estratégia a pesquisa-intervenção. Cartografar é acompanhar processos apresentados aqui na modalidade relato de experiência. Esta experiência consta de discussões e reflexões em equipe, no desafio de cuidar de um paciente jovem, de difícil relacionamento interpessoal, tendo a sua subjetividade como questão disparadora do cuidado real. Resultados: a vivência como enfermeira e doutoranda em um hospital referência em pneumologia, propiciou acompanhar e refletir sobre as principais dificuldades enfrentadas pela equipe de saúde no cuidado a este tipo de paciente. Desta reflexão, foram mapeados aspectos significativos da assistência, considerando a subjetividade como tecnologia e um dos balizadores assistenciais. Subjetividade entendida não apenas como algo abstrato, mas como uma dimensão ampliada da vida concreta, dos modos de viver e dos projetos de vida da pessoa. o foco de atenção será um destes pacientes, pseudônimo Vitório. Dependente de oxigênio, repouso absoluto, recusa todos os procedimentos, mesmo os essenciais como alimentação e higiene. Agressivo, em suas atitudes expressa intenso sofrimento e consciência dos limites com seu mundo interno, desafio para a equipe - um dos mapas cartografados. Solitário, evidenciando a fragilidade de laços afetivos. Envolvida nos projetos assistenciais, a enfermagem se mobiliza, buscando alternativas pautando-se nos referenciais de subjetividade como tecnologia leve para se escutar, aproximar-se, criar espaços para relacionamento interpessoal e comunicação. ao discutir sobre necessidades, circunstâncias de vida e adoecimento de Sr. Vitório, algumas demandas foram consideradas manifestações de sua subjetividade: novo mapa construído. Suscitar estas reflexões durante a passagem de plantão mostrou-se estratégia significativa para um cuidado sutil ao cliente: um dos mapas desse processo. Outro mapa foi a construção conjunta de uma proposta de cuidados amenizando julgamentos, criando vínculos e culminando com um cuidado ético e integralizado e entrosamento entre paciente e equipe. Conclusões: a cartografia permitiu acompanhar as reflexões da equipe de enfermagem, extraindo de seus mapas o cuidado sutil e genuíno; envolvendo-se na assistência, considerando subjetividades e oferecendo ao paciente alternativas para atendimento de necessidades básicas, devolvendo-Ihe dignidade e autonomia.

Soares, Rosimeire Angela de Queiroz; Machado, Ana Lucia; Bigato, Karen Steagall; Santos, Livia Giubilei; Pigozi, Pamela Lamarca; Cozzani, Rosana Regina; Santos, Sara Giubillei. Devolvendo a Dignidade e Autonomia: Cartografia de um Cuidado. In: Anais do Congresso Internacional de Humanidades \& Humanização em Saúde [= Blucher Medical Proceedings, num.2, vol.1]. São Paulo: Editora Blucher, 2014. ISSN 2357-7282 DOI 10.5151/medpro-cihhs-10510 